\title{
Building and Nurturing Trust Among Members in Virtual Project Teams
}

\author{
Jelena M. Lukić \\ Modern Business School, Belgrade, Serbia \\ Milana M. Vračar \\ Modern Business School, Belgrade, Serbia
}

\begin{abstract}
The Fourth Industrial Revolution has brought significant changes in the field of organizational design, especially in terms of how work is structured, organized, and conducted. One of the major trends widely adopted by numerous businesses worldwide is the establishment of virtual project teams, which allows members to work from remote locations regardless of their time zone, nation or culture and to collaborate using various information systems and technologies. Advantages of virtual project teams observed in terms of cost reduction, productivity growth, knowledge, skills, and flexibility are obvious and cannot be neglected. Nevertheless, challenges do often appear, and need to be addressed in order to create successful virtual organizations. The objective of this paper is to examine the role and importance of trust in virtual project teams, and to propose methods and activities that can help establish and nurture trust among employees in remote teams.
\end{abstract}

\section{Keywords}

Organizational behavior, team-based structures, virtual project teams, trust, employees, information and communication technologies.

\section{Introduction}

Modern information and communication technologies (ICT) and their continuous development have changed not only the manner in which organizations operated, but also their organizational structures, management and leadership (Luo, Van de Ven, Jing \& Jiang, 2018; Snow, Fjeldstad \& Langer, 2017). Many organizations, no matter in which industries they operate, have established team-based organizational structures, which provided them with necessary flexibility, decentralized decision-making, greater collaboration and knowledge transfer among employees (Miles, Snow, Fjeldstad, Miles \& Lettl, 2010; Tannenbaum, Mathieu, Salas \& Cohen, 2012). With the evolution of information and communication technologies, from the early 1980s until now, many organizations have established virtual teams - groups of geographically dispersed employees that are linked via different forms of technologies in order to accomplish organizational/project tasks (Townsend, DeMarie \& Hendrickson, 1998).
Members in virtual project teams can work from remote locations equipped with electricity, computer and Internet access. Those conditions offer employees the opportunity to organize their working time effectively in order to make a good balance between their private and professional lives (Lazarević \& Lukić, 2016; Slavić, Bjekić \& Berber, 2017). Responsibilities and duties of employees in virtual project teams are the same as those of traditional teams, whose members are physically at the same place; however, virtual work changes the way in which employees engage and interact with each other. Naturally, there are many concerns about achieving effective teamwork among employees that are geographically separated (Lukić, 2014). Many authors emphasized that trust was a factor of critical importance for success in virtual project teams (Brewer, 2015; Daim et al., 2012; Greenberg, Greenberg \& Antonucci, 2007; Jawadi, Daassi, Kalika \& Favier, 2007; Leeds, 2008; Lencioni, 2002), while executives and managers of successful companies also 
stated that ,there is no team without trust" (Delizonna, 2017). Recent studies have also found that building and maintaining trust in an organization would be among key organizational challenges of the future, as organizations would be judged on theirs trust and fairness (Brown et al., 2017).

The objective of this paper is to examine the role and importance of trust in virtual project teams, and to propose methods and activities that can help establish and nurture trust among employees in remote teams. The first part of the paper discusses trust as one of the challenges remote teams face, and suggests possible solutions to the proper management thereof. It also studies research results found by the Remote.co team, and affirms the importance of trust for successful virtual project team organization. The second part of the paper concludes with a statement confirming the possibility of efficiently creating a culture of trust within a virtual project team through the application and adoption of a number of methods and activities.

\section{The importance of collective trust in virtual project teams}

Trust has been positioned as an important research topic in management, especially in communication, leadership, negotiation, game theory, and teamwork (Mayer, Davis \& Schoorman, 1995). Additionally, trust also acts as a supplement for control and coordination mechanisms (Julsrud \& Bakke, 2008), and as an important ingredient of the overall organizational functioning (Ning, Yin \& Mingxuan, 2007). It is proved that employees achieve greater results and have higher levels of organizational commitment when they trust each other, their managers, and leaders (Galford \& Drapeau, 2003). Trust refers to honesty, fairness, and quality of relationships among employees within an organization (Holton, 2001; Hurley, 2006; Pelsmaekers, Jacobs \& Rollo, 2014), with the main aim to ensure good employee relations, especially under ambiguous and uncertain conditions (Dietz, Gillespie \& Chao, 2010). The literature on trust in traditional teams specified that trust led to positive work relationships, more open communication, cooperation, and a higher quality of decision-making (Krot \& Lewicka, 2012). Consequently, the existence of trust is associated with high-performing teams (El-Sajjade \& Wilkins, 2017; Jawadi et al., 2007; Kanawattanachai \& Yoo, 2005).
Over the last two decades, virtual teams have been growing at a fast pace, and the challenges of their organization and management have increased accordingly (Ferrazzi, 2014; Petković, Orelj \& Lukić, 2014; Pullan \& Prokopi, 2016). One of the ingredients that is often overlooked, but very important - especially in virtual teams - is trust (Brewer, 2015; Greenberg, Greenberg \& Antonucci, 2007; Leeds, 2008). The absence of traditional mechanisms of coordination and control makes it necessary for virtual team members to rely on interpersonal trust - expectations and beliefs about other members' actions (Shin, 2004). Trust in virtual team reflects how much employees believe in each other (Jawadi et al., 2007). In situations where trust exists among team members, there is a strong belief that each member will make commitments, and act upon good intentions on behalf of the whole group (Chang, Hung \& Hsieh, 2014).

In this paper secondary research was conducted by using the results of Remote.co team that, among others, collected the answers from leading remote global companies about key challenges that they virtual teams faced. Using an online tool (Worditout n.d.), the authors of the paper created a word cloud, i.e. a visual representation of words as per the importance and frequency of use by remote workforce/teams. The answers to the question "What elements are key to successful working relationships with remote teams?" were input in above-mentioned online tool. Results are given in Figure 1.

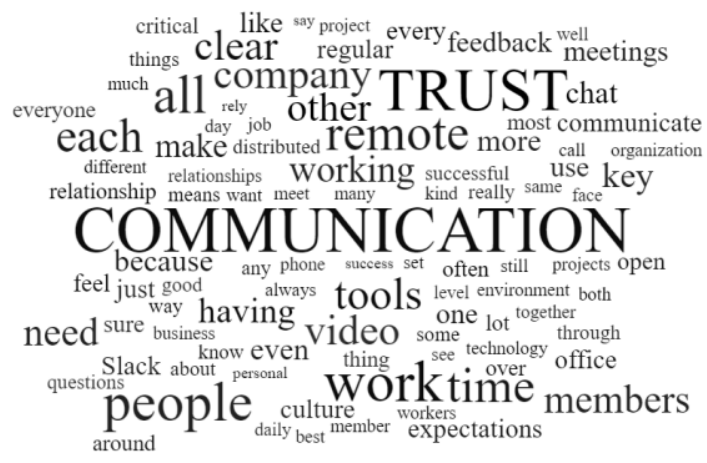

Figure 1 The most frequent words in answers regarding the key success elements in remote teams

Source: Authors (Answers of respondents available at Remote.co, n.d., pasted and formatted in: Worditout n.d.)

The analysis of the answers provided by 71 leading remote global companies regarding the elements of successful working relationships within remote teams showed that trust and communication were most commonly demanded and 
valued. Knowing that in a fast-paced, remote environment, cultural differences, stereotypes, pressures, and potential misinterpretations could negatively impact a team's performance, it is understandable why virtual organizations emphasize the importance of these two concepts. Furthermore, a number of studies showed that there was a relationship between communication and trust "communication processes are the key underlying mechanisms for establishing trust" (Gibson \& Manuel, 2003, p. 69). Through constant, direct, and honest communication, virtual organizations can enhance a sense of belonging, thus promoting a collaborative, supportive environment based on trust, integrity, and cohesiveness. With such organizational structure, it is more likely that a team will yield better results, as its members will be more enthusiastic and driven to achieve success.

Table 1 contains excerpts from the answers given by remote companies, which clearly depict their attitude toward trust among members in virtual project teams.

Table 1 Excerpts from the answers by remote companies, which depict their attitude toward trust

\section{"As we work in a results-only work environment, trust of our colleagues and one another is of the utmost importance." ICUC Social}

"When people can't physically see each other much of the time, trust becomes all the more important." Answer Connect

"Trust is a key element; you have to ensure that every member of the team trusts each other to do what they have agreed to." Mavens

"Trust. Trust. Trust. It needs to be given freely and earned daily. When it works, it is a thing of beauty." Pagely

Source: Adapted from Remote.co, n.d

\section{Methods and activities for building and nurturing trust in virtual project teams}

Over the years, it has become evident that it was more difficult and time-consuming to develop trust in virtual teams in comparison with traditional teams (Brewer, 2015; Lee, 2014). However, similarly to how it is done in a traditional, face-toface team, it is possible to build trust in a remote team, with a number of carefully planned methods and activities that are based on different trust dimensions - ability, integrity, and benevolence (Clark, Clark \& Crossley, 2010). These methods and activities are linked to and highly dependent on the organizational structure, values, and vision, as well as personal characteristics of each team member. Some of the standard, yet fundamental methods and activities include adopting a special approach to the recruitment and selection process, hiring an effective team leader, establishing behavioral controls, implementing performance evaluation and rewarding systems, raising awareness of swift trust, maintaining positive organizational culture and climate, as well as regular and reliable communication (virtual team meetings, occasional face-to-face meetings), and organizing team-building activities (Figure 2).

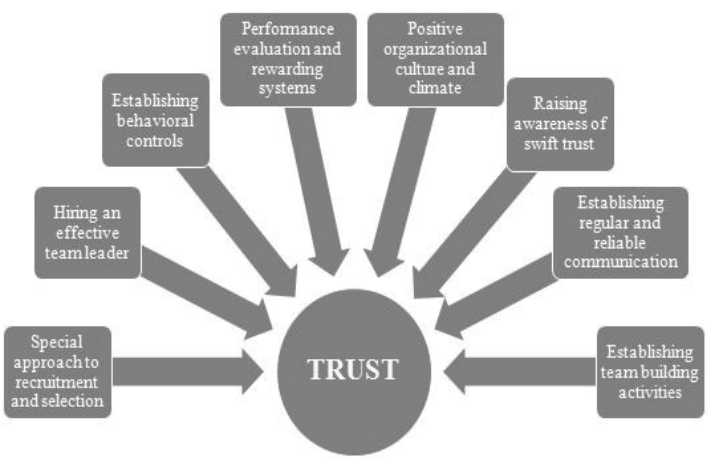

Figure 2 Proposed methods and activities for building and nurturing trust among employees in virtual project teams

Source: Authors

\subsection{Special approach to the recruitment and selection process}

When recruiting employees for virtual team, a hiring manager should consider more than a person's ability and willingness to work remotely (Lukić, 2014). Hiring managers need to assess the abilities of a person to perform any necessary, job-related tasks, but they also need to ensure they hire people who demonstrate strong moral principles, and who are willing to take part and contribute to team success as much as possible. Bradley and Vozikis (2004) summarized traits which virtual team members should have to enhance trust:

- Ability to work with the technology used by the team;

- High degree of functional area competency;

- High integrity;

- High propensity to trust;

- Excellent communication skills;

- Openness to innovation and ideas suggested by others;

- Cultural and social sensitivity. 


\subsection{Hiring an effective team leader}

The team leader selection process is very important because leaders are the ones to promote communication within the group, provide constant feedback, establish group norms, stimulate creative thinking, problem solving, and knowledge sharing (Apenko, 2014). All of the mentioned activities lead to trust among team members, but also between team members and their leader. Furthermore, it is important to emphasize that shared leadership in virtual project teams could be very useful for increasing a sense of belonging and organizational commitment of team members (Brake, 2016). When each team member applies knowledge, skills, and abilities to lead a part of a project, for which they are qualified enough, they feel empowered and become more committed. Bradley and Vozikis (2004) suggested several things which leaders should consider when it comes to establishing and fostering trust in virtual project teams:

- Leaders should establish official communication guidelines;

- Leaders should precisely outline a team mission, with explicit objectives and clearly defined roles and responsibilities;

- Leader should consider social aspects of team development;

- Leader should consider cultural differences of team members.

A leader's contribution and actions are paramount because they serve as the basis for creating a pleasant working environment, and even preventing conflicts.

\subsection{Establishing behavioral controls}

A set of predefined rules used to guide desired behaviors of team members could be very useful for building trust among employees in virtual project teams because it is how team members become more aware of what they can expect from their colleagues (Dennis, Robert, Curtis, Kowalczyk \& Hasty, 2012). In addition to the formalization of organizational norms and procedures, behavioral controls can be established through the roles of team members. Each team member has at least one role within a team, which clearly defines the responsibilities of that member. By removing potential misunderstandings regarding the role of team members, organizations are providing a precise guidance on how team members should interact with each other (Clark, Clark
\& Crossley, 2010), so that each team member knows what they should do, and what to expect from others. Furthermore, it is very important to manage daily activities of team members regarding status reports, project timelines, documentation, deadlines, etc. (Abudi, 2012).

\subsection{Performance evaluation and rewarding systems}

Each team member should be familiar with performance evaluation methods and expectations in their organization, because knowing that their results are monitored and evaluated, team members are more likely to work in the planned manner (Dennis et al., 2012). Reward systems should allow risk-taking without punishment if performance is worse than planned (Clark, Clark \& Crossley, 2010). Constant feedback, discussions reflected through positive and productive criticism, recognition, and praise are a particular way to establish trust as each person can feel less isolated, and more like part of a real team. Virtual team managers need to incorporate proper ways of assessing their remote workforce, and avoid focusing on the negative exclusively, as it might affect employee performance and harm communication. Therefore, performance reviews should be balanced, naturally, if appropriate.

\subsection{Positive organizational culture and climate}

Team members in virtual project teams usually have different cultural backgrounds. Therefore, their attitudes, values, norms, and behaviors might differ (Staples \& Zhao, 2006), which may be a source of potential misunderstandings. Team leaders and managers should establish a new, unique organizational culture and climate that everyone in the company should accept and respect. Yet, it is more about working in a collaborative environment, where participants are gathered to deliver results, and achieve goals, united around the values they all share, than it is about forcing anyone into respecting principles and beliefs they otherwise would not. Organizational culture and climate should be promoted directly on a company's website, integrated into daily work, and explained to applicants during the interview process in order to avoid any future incompatibilities and issues. A positive team climate will certainly reduce the intensity and negative effects of conflicts, as it is built on firm attitudes and mutual understanding that everyone benefits from. 


\subsection{Raising awareness of swift trust among remote workers}

Twenty-two years ago, Meyerson and co-authors developed the concept of swift trust, a form of trust occurring in temporary team organizations (Meyerson, Weick \& Kramer, 1996). According to this paradigm, trust is assumed rather than developed, and based on shared tasks and actions, not on similarities or/and differences of individuals forming a team (Jarvenpaa \& Leidner, 1999). In a temporarily-built remote team, it is important to raise awareness of trust based on common objectives, roles, responsibilities, and recognized expertise, as there is not much time or need to gradually build trust. Each virtual team member should acknowledge the fact that all of the members are in the same situation regarding the success or failure of their results, and that they do not have many options, but to trust each other from the very beginning of a project (Ferrazzi, 2014).

\subsection{Establishing regular and predictable communication among team members}

Research has showed that the level of trust was higher in virtual teams, where members exchanged information and communicated regularly, than in teams, whose members did not communicate often (Mize, 2016). In order to build and nurture trust, team members should all be informed of any news regarding other members, such as their current/future projects, absence, sickness leave, vacation dates, etc. They need to be able to develop friendly relationships with their colleagues, which is why their company should provide them with opportunities to meet and enjoy conversations about topics other than business. Nonetheless, for all work-related questions, doubts, projects, activities, requirements, and specifications, it is impossible to predict success unless everything is precisely explained and shared across teams. Communication can be enhanced through: virtual team meetings and occasional face-to-face meetings. Weekly staff meetings, in which virtual employees meet each other through modern ICT is a way of maintaining constant communication. This helps improve confidence of team members, but also discuss major points on the agenda in a faster and more direct way than it would have been done through written communication. Even though not all of the remote workers will participate equally, they should be encouraged to ask and state their opinion whenever possible. Managers of virtual teams often organize face-to-face meetings for all team mem- bers (Brewer, 2015). They may ask that all employees come to the office a few times per year in order to build stronger relationships with their remote colleagues. Additionally, in the initiation phase of a new project, team members often prefer having face-to-face meetings, where they can interact and connect more easily (Dube \& Pare, 2004), which is also very beneficial for the company itself, as its team can find solutions and explore ideas they might not consider if planning remotely.

\subsection{Establishing team-building activities}

In terms of team-building, face-to-face meetings can strengthen team relationships, as such encounters help them learn more about each other, and do things they could not do together virtually (play sports, eat, go out). These activities help build a stronger remote community, as they encourage conversation and collaboration. Finally, in-person gatherings help understand the importance of team spirit, as every team member gets the opportunity to understand the role and contribution of every individual on a team on a deeper level.

\section{Conclusion}

Given the fact that hiring remotely might cause a number of issues in terms of security, confidentiality, and social differences, it is of vital importance to clearly define the structure and policies an organization wants to foster among its team in order to create a culture of trust. As the practice of virtual teamwork increases, numerous team management challenges start to appear. One of such challenges is establishing and nurturing trust among members of virtual project teams that have never met or worked with each other before, especially if the chances of working together in the future are less probable. Therefore, organizations should carefully conceptualize their approaches to remote business, based on their values, available resources, and project requirements. Depending on whether teams are working on short-term or long-term projects, trust can be achieved in different ways, while less attention is given to the projects of shorter duration, where trust is more assumed, than built through successful relationship building activities that require more time and dedication.

The aim of this paper was to stress the importance of trust, and describe some of the most common methods and activities used to build and 
nurture trust in virtual project teams. The analysis of the Remote.co research results showed that trust and communication were indispensable for success in virtual project teams. Yet, in a remote team, it is not always easy to establish trust as its members are not communicating directly, but via online tools, which makes it more daunting - but not impossible. Some of the suggestions proposed in this paper include adopting a special approach to the recruitment and selection process, hiring an effective team leader, establishing behavioral controls, implementing performance evaluation and rewarding systems, raising awareness of swift trust, maintaining positive organizational culture and climate, as well as regular and reliable communication (virtual team meetings, occasional face-to-face meetings), and organizing teambuilding activities.

Even though working in virtual project teams can enchain significant issues and failures if organized wrongly, it is important to realize how many advantages the widespread of virtual work has to offer, especially in terms of cost reduction, innovation, and business expansion. Therefore, with efficient organization and management, any business with adequate resources can embrace new trends and benefit from such practices. SM

\section{References}

Abudi, G. (2012). Best practices for managing and developing virtual project teams. Paper presented at PMI ${ }^{\circledR}$ Global Congress 2012 North America, Vancouver, British Columbia, Canada. Newtown Square, PA: Project Management Institute.

Apenko, S. N. (2014). Leadership of Human Resources and Project Teams in the Management of Strategic Changes in the Organisation. Strategic Management, International Journal of Strategic Management and Decision Support Systems in Strategic Management, 19 (1), 28-34.

Bradley, W. E., \& Vozikis, G. S. (2004). Trust in Virtual Teams. In Godar, S. H., Ferris, S. P. (Eds.), Virtual and Collaborative Teams (pp. 99-115). IDEA Group Publishing.

Brewer, P. E. (2015). International Virtual Teams, Engineering Global Success. New Jersey: IEEE Press.

Brake, T. (2016). 5 lessons for building trust on a virtual team. Retrieved January 15, 2018, from: http://www.tmaworld.com/our-thinking/5-lessonsbuilding-trust-virtual-team

Brown, J., Gosling, T., Sethi, B., Sheppard, B., Stubbings, C., Svioka, J., Williams, J., \& Zarubina, D. (2017). Workforce of the future, The competing forces shaping 2030, PWC.

Chang H. H., Hung, C. J., \& Hsieh, H. W. (2014). Virtual teams: cultural adaptation, communication quality, and interpersonal trust. Total Quality Management, 25 (12), 1318-1335.
Clark, W. R., Clark, L. A., \& Crossley, K. (2010). Developing Multidimensional Trust Without Touch in Virtual Teams. The Marketing Management Journal, 20 (1), 177-193.

Daim, T. U., Ha, A., Reutiman, S., Hughes, B., Pathak, U., Bynum, W., \& Bhatla, A. (2012). Exploring the communication breakdown in global virtual teams. International Journal of Project Management, 30, 199212.

Dietz, G., Gillspie, N., \& Chao G. (2010). Unravelling the complexities of trust and culture. In Saunders, M.N.K., Skinner, D., Dietz, G., Gillspie, N., \& Lewicki, R. I. (Eds.), Organizational Trust: A Cultural Perspective. UK: Cambridge University Press.

Dennis, A., R., Robert, L. P., Curtis, A. M., Kowalczyk, S. T., \& Hasty, B. K. (2012). Trust Is In the Eye of the Beholder: A Vignette Study of Postevent Behavioural Controls Effects on Individual Trust In Virtual Teams. Information Systems Research, 23 (2), 546-558.

Delizonna, L. (2017). High-Performing Teams Need Psychological Safety. Here's How to Create It. Retrieved January 16, 2018, from https://hbr.org/2017/08/high-performing-teams-needpsychological-safety-heres-how-to-createit?referral=03759\&cm_vc=rr_item_page.bottom

Dube, L., \& Pare, G. (2004). The Multi-Faceted Nature of Virtual Teams, Projects, Protocols and Processes, PA: Idea Group, 1-39.

Es-Sajjade, A., \& Wilkins, T. (2017). Design, Perception and Behavior in the Innovation Era: Revisiting the Concept of Interdependence. Journal of Organization Design, 6 (12), 1-12.

Ferrazzi, K. (2014). Getting Virtual Teams Right. Harvard Business Review. Retrieved March 12, 2018, from https://hbr.org/2014/12/getting-virtual-teamsright? referral=03759\&cm_vc=rr_item_page.bottom

Galford, R. M., \& Drapeau, A. S. (2003). The Enemies of Trust. Retrieved January 12, 2018, from https://hbr.org/2003/02/the-enemies-of-trust

Gibson, C. B., \& Manuel, J. A. (2003). Building Trust: Effective Multicultural Communication Processes in Virtual Teams. In Gibson, C. B., Cohen, S. G. (Eds.), Virtual Teams That Work, Creating Condition for Virtual Team Effectiveness (pp. 59-89). Jossey - Bass.

Greenberg, P. S., Greenberg, R. H., \& Antonucci, Y. L. (2007). Creating and Sustaining Trust in Virtual Teams. Business Horizons, 50 (4), 325-333.

Holton, J. (2001). Building Trust and Collaboration in a Virtual Team. Team Performance Management: An International Journal, 7 (3), 36-47.

Hurley, R. F. (2006). The Decision to Trust, Harvard Business Review, Retrieved January 11, 2018, from https://hbr.org/2006/09/the-decision-to-trust.

Jarvenpaa, S., \& Leidner, D. (1999). Communication and Trust in Global Virtual Teams. Organization Science, 10 (6), 791-815.

Jawadi, N., Daassi, M., Kalika, M., \& Favier, M. (2007). Virtual Teams: The Role of Leadership in Trust Management, In Brennan, L. L., Johnson, V. E. (Eds.), Computer-Mediated Relationships and Trust, Managerial and Organizational Effects. New York: Information Science Reference.

Julsrud, T. E., \& Bakke, J. W. (2008). Building Trust in Networked Environments: Understanding the Importance of Trust Brokers. In Brennan, L. L., Johnson, V. E. (Eds.), Computer-Mediated Relationships and Trust - Managerial and 
Organizational Effects (pp. 117-139). New York: Information Science Reference.

Kanawattanachai, P., \& Yoo, Y. (2005). Dynamic Nature of Trust in Virtual Teams. Sprouts: Working Papers on Information Environments, Systems and Organizations, 2(2), 42-58.

Krot, K., \& Lewicka, D. (2012). The Importance of Trust in Manager-Employee Relationships. International Journal of Electronic Business Management, 10 (3), 224-233.

Lazarević, S., \& Lukić, J. (2016). The impact of information and communication technology on human resources. Sinteza 2016 International Scientific Conference on ICT and E-business related research (pp. 369-375), Belgrade: Singidunum University.

Leeds, B. (2008). Trusting Remote Workers. In Brennan, L. L., Johnson, V. E. (Eds.), Computer-Mediated Relationships and Trust - Managerial and Organizational Effects (pp. 89-100). New York: Information Science Reference.

Lee, M. R. (2014). Leading Virtual Project Teams, adapting leadership theories and communications techniques to 21st century organizations. Taylor \& Francis Group, CRC Press.

Lencioni, P. (2002). The Five Dysfunctions of a Team. A Leadership Fable. Jossey-Bass.

Lukić, J. (2014). The role of information and communication technology in a virtual organization: challenges for virtual employees, 1st International Academic Conference PLACES AND TECHNOLOGIES (pp. 1098-1105), Belgrade: Faculty of Architecture.

Luo, J., Van de Ven, A., Jing, R., \& Jiang Y. (2018). Transitioning from a hierarchical product organization to an open platform organization: a Chinese case study. Journal of Organization Design, 7 (1), 1-14.

Mayer, R. C., Davis, J. H., \& Schoorman, F. D. (1995). An Integrative Model of Organizational Trust. Academy of Management Review, 20 (3), 709-734.

Meyerson, D., Weick, K.E., \& Kramer, M.R. (1996). Swift trust and temporary groups. In M.R., Kramer, T.R., Tyler (Eds.), Trust in organizations, Frontiers of theory and research (pp. 166-195). Thousand Oaks, CA: Sage Publications.

Miles, R. E., Snow, C. C., Fjeldstad, Ø. D., Miles, \& G. Lettl, C. (2010). Designing Organizations to Meet 21stCentury Opportunities and Challenges. Organizational Dynamics, 39 (2), 90-103.

Mize, Ch. (2016). How to Build Trust on Virtual Teams, Retrieved January 16, 2018, from https://www.pgi.com/blog/2016/06/build-trust-virtualteams/.

\section{$\triangle$ Correspondence}

\section{Jelena M. Lukić}

Modern Business School, Belgrade, Serbia

Terazije 27/IV, 11000, Belgrade, Serbia

E-mail: jelena.lukic@mbs.edu.rs
Ning, L., Yin, Y., \& Mingxuan, J. (2007). How does organizational trust benefit work performance? Frontiers of Business Research in China, 1 (4), 622-637.

Pelsmaekers, K., Jacobs, G., \& Rollo, C. (2014). Trust and discursive interaction in organizational setings. In Pelsmaekers, K., Jacobs, G., \& Rollo, C. (Eds.), Trust and Discourse: organizational perspectives (pp. 1-10). Amsterdam/Philadelphia: John Benjamins Publishing Company.

Petković, M., Orelj, A., \& Lukić, J. (2014). Managing employees in a virtual enterprise (pp. 227-232), Singidunum University International Scientific Conference - Impact of Internet on Business Activities in Serbia and Worldwide, Belgrade, University of Singidunum.

Pullan, P. \& Prokopi, E. (2016). Leading virtual project teams: dos and don'ts. Paper presented at PMI® Global Congress 2016 EMEA, Barcelona, Spain. Newtown Square, PA: Project Management Institute.

Slavić, A., Bjekić, R., Berber, N. (2017). The Role of the Internet and Social Networks in Recruitment and Selection Process. Strategic Management, International Journal of Strategic Management and Decision Support Systems in Strategic Management, 22 (3), 36-43.

Staples, D. S., \& Zhao, L. (2006). The Effects of Cultural Diversity in Virtual Teams Versus Face-to-Face Teams. Group Decision and Negotiation, 15 (4), 389-406.

Shin, Y. (2004). A Person-Environment Fit Model for Virtual Organizations. Journal of Management, 30 (5), 725743.

Snow, Ch., Fjeldstad, D., \& Langer, A. (2017). Designing the digital organization. Journal of organization Design, $6(7), 1-13$.

Tannenbaum, S. I., Mathieu, J. E., Salas, E., \& Cohen, D. (2012). Teams Are Changing: Are Research and Practice Evolving Fast Enough? Industrial and Organizational Psychology, 5, 2-24.

Townsend A. M., DeMarie S. M., \& Hendrickson A. R. (1998). Virtual teams: Technology and the workplace of the future. Academy of Management Executive, 12, 1729.

Remote.co (n.d.), Retrieved February 25, 2018, from https://remote.co/qa-leading-remote-companies/whatelements-are-key-to-successful-working-relationshipswith-remote-teams/

Worditout (n.d.), Retrieved February 26, 2018, from https://worditout.com/word-cloud/create 